Antti Laherto (MSc) works in teacher education at the Department of Physics, University of Helsinki, and co-ordinates a resource centre for physics teachers and students. His research interest is education in contemporary science and technology, both in formal and in informal learning environments.

ANTTI LAHERTO

Department of Physics

University of Helsinki, Finland

antti.laherto@helsinki.fi

\title{
Incorporating nanoscale science and technology into secondary school curriculum: Views of nano-trained science teachers
}

\begin{abstract}
The growing societal significance of nanoscience and nanotechnology (NST) entails needs for addressing these topics in school curricula. This study lays groundwork for responding to those needs in Finland. The purpose was to analyse the appropriateness of NST for secondary school curriculum contents. First, a week-long in-service teacher training course was arranged on content knowledge of NST. After attending the course, 23 experienced science teachers were surveyed regarding their views on the educational significance of these issues, and on prospects for including them into the curriculum. A questionnaire with open-ended questions was used. Qualitative content analysis of the responses revealed that the respondents considered NST as desirable contents for secondary school, but arranging instruction is problematic. The teachers emphasised the educational significance of many applications, scientific principles and ethical issues related to NST. The outcomes are discussed with reference to recent studies on teachers' barriers and educational concerns regarding NST.
\end{abstract}

\section{INTRODUCTION}

\section{Background \& Purpose}

NST are advancing rapidly, and increasingly significant societal and economical prospects are attached to these emerging fields. Consequently, providing education in NST at different levels has been called for throughout the world. These demands have been made from a variety of viewpoints, related to the general challenges of education in science, technology, engineering and mathematics (STEM).

Firstly, the common concern for many STEM-fields, the increasing need for researchers and other professionals, is pronounced in the rapidly growing fields of NST. In the coming years the employment markets will most likely run short of scientists and engineers with specialization in nanoscale issues (Brune et al., 2006; European Commission, 2010; Ministry of Education, 2005). Secondly, several advocates of NST education base their arguments on the need to enable citizens in making informed decisions on nanoscience-related societal issues (e.g. Stevens, Sutherland \& Krajcik, 2009; Zenner \& Crone, 2008). NST education has also been motivated with reference to the prospects of nanotechnology involving both benefits and risks regarding environment and health, as well as a few other ethical concerns (Moor \& Weckert, 2004). Some level of understanding of 
related science and technology is needed in order to make sense of the debate and to deal with these promises and concerns in a balanced and responsible way. Futhermore, some science educators have proposed that NST, among some other contemporary sciences, should be discussed in school simply because it makes school science more interesting, topical and relevant to students. All these demands have also been doubted and challenged by the critics of "nanohype" (see e.g. Mitchell, 2007).

This study addresses the perceived need for NST education (for a further discussion on the educational need, see Laherto, 2010), and lays groundwork for curriculum revision responding to that need. The purpose of the study was to initiate such a process in Finland by learning from the views of NST-informed science teachers on the needs and prospects of NST education in secondary schools. This approach is motivated by teachers' integral role in the curricular process and "makeor-break" role in any curriculum innovation (Kelly, 2004). Research has shown that teachers' perspectives must be investigated and taken into account in order to facilitate curriculum change (Anderson \& Helms, 2001; Peers, Diezmann \& Watters, 2003; van Driel, Beijaard \& Verloop, 2001).

Analysing the needs and prospects of including a new field into the curriculum requires informants with an understanding of the field in question. It may be assumed that teachers are not familiar enough with the novel fields of NST. In order to ensure the competence of the surveyed teachers, they were trained in NST content knowledge before filling in a questionnaire. The research question of the study is: What opinions do the NST-trained science teachers have about NST education in secondary schools?

\section{Theoretical framework}

A part of the study's aim was to bring out Finnish teachers' conceptions of barriers that hinder the incorporation of NST into secondary school science. In this respect, the results are compared with literature on teachers' barriers in revising science teaching. In-service training and teachers' learning in networks have been shown as effective in breaking down barriers that are intrinsic to the teachers, relating to teachers' knowledge, beliefs and self-efficacy (Bamberger \& Krajcik, 2010; van Driel et al., 2001). Ertmer (1999) called these types of barriers "second-order barriers" while discussing strategies for technology integration. However, teachers also face a number of extrinsic, "first-order barriers" (ibid) that prevent them from reforming their teaching: time constraints, limitations stemming from the standards, and lack of instructional materials, for instance (cf. Peers et al., 2003). In the context of NST, a recent study by Bamberger and Krajcik (2010) pointed out that it is crucial to deal with such extrinsic barriers in order to enable NST teaching.

In the study reported here, however, the teachers were surveyed not only regarding the constraints they perceive, but they were also asked to analyse the need for NST education on a more general level. That is, they were not only asked how NST could be incorporated into the curriculum, but also why it should - or should not - be included, and if it should, what would be the central contents. This approach reflects the relatively deep involvement of teachers in curriculum development processes that is typical for the Finnish educational system (see e.g. Pehkonen, Ahtee \& Lavonen, 2007). Since teachers in Finland are generally involved not only in implementing but also in formulating the curriculum, it is natural to begin any process of curriculum amendment by listening to experienced teachers' conceptions. This view - making teachers engage with educational reforms already in an early phase - is widely supported also in the literature (see e.g. Anderson \& Helms, 2001; Kelly, 2004; van Driel et al., 2001).

This study, thereby, also surveyed teachers' views on the content area's educational significance. Here, this concept is used with reference to the Model of Educational Reconstruction (Duit, Komorek \& Wilbers, 1997). The model was designed with the specific purpose of providing a "theoretical framework for studies as to whether it is worthwhile and possible to teach particular areas 
of science" (Duit, 2007, p. 5). Accordingly, the model has previously been employed in scrutinising comparatively novel fields of science - ones that are not yet in the school curriculum - such as the chaos theory (Duit et al., 1997). On the basis of the previous cases, the model appears to be suitable for analysing the emerging fields of NST from an educational perspective. This approach fits with the philosophic tradition of curricular inquiry that asks whether "children should be taught certain things or in certain ways, based on what we believe are just and appropriate educational goals and means" (Darling-Hammond \& Snyder, 1992, p. 41).

The Model of Educational Reconstruction typically involves several studies and a variety of research approaches and methods. The study reported here deals with only one component of an educational reconstruction of NST, analysis of educational significance. While methods in this component are mostly hermeneutic-analytical, Duit (2007, p. 8) also points out the possibility to use empirical methods - such as expert questionnaires or Delphi studies - to analyse large domains. Accordingly, Komorek, Wendorff and Duit (2002) carried out an empirical study to find out experts' views on the educational significance of non-linear physics. In a similar fashion, the study reported here contributes to the analysis of educational significance of NST by surveying a group of "experts", i.e. NST-trained science teachers.

The aim of pointing out educationally central aspects of NST makes this study similar to the Delphi studies carried out in the U.S. (Stevens et al., 2009; Wansom et al., 2009). In those comprehensive studies, a variety of experts in NST and in STEM education compiled lists of "Big Ideas" of nanoscale science and engineering that should be incorporated in the curriculum. Those results will be compared with the ones obtained in this study.

\section{Research Frame \& Method}

\section{Setting: Course in Nanoscience and nanotechnology}

The survey was carried out in the context of an in-service teacher training course on NST, 2-6 June 2008, that was arranged by the Department of Physics at the University of Helsinki. The course was open for all science teachers, and it was publicized by posting an announcement to all the secondary schools of Southern Finland. Information about the course was also posted on the web pages of the Department of Physics and on an electronic bulletin for science teachers; 29 teachers registered and attended the course.

The course programme is described here in detail, since it has implications concerning the validity of the study. The content of the course was planned by four professors from the Faculty of Science in the University of Helsinki. The planning committee members had been working in a variety of NST-related research for years, and three of the professors were co-ordinating national networks of all nanoscale research in Finland. Thus, the planning committee had a broad understanding of the fields of NST and the competence to design a comprehensive course on nanoscale science and engineering as requested.

The course programme, then, included altogether 22 hours of lectures and 6 hours of visits during five days (the full programme of the course can be found at http://per.physics.helsinki.fi/ FTK2008/). The lectures were given by researchers from the University of Helsinki and the Helsinki University of Technology. The course started with three lectures covering the basics of nanoscale science and engineering: the fundamental concepts and phenomena, basic research methodologies (especially the microscopy instrumentations), as well as some quantum mechanics. As the course continued, a variety of lectures deepened participants' understanding of research methods, fabrication techniques and properties of nanoparticles and nanostructures. Nanoscale research and technology in biosciences was introduced and the biological effects of nanoparticles 
discussed during several lectures. One lecture acquainted the course participants with the basics of nanophotonics. Furthermore, nanotechnological applications were thoroughly discussed during the course: medical applications, electronics and spintronics as well as a variety of other applications utilising mechanic, optical, electric, magnetic, thermal or biological properties of nanoscale particles or structures. Ethical concerns - especially the risks of nanotechnology regarding health and the environment - were focused on in three lectures. The course concluded with a presentation on the future visions of NST.

Besides the lectures, some guided tours in research laboratories and a visit to a nanotechnologyrelated enterprise were also included in the programme. The laboratory tours presented the teachers with the methods and processes of NST-related research in atmospheric sciences, experimental subatomic physics, nanomaterials, and applied x-ray physics. The commercial potential of NST was discussed when the participants visited a medical company that applies nanotechnology to the development of diagnostic tests.

Additionally, the course included three presentations that addressed educational issues. The first one presented results of international surveys on the general public's awareness of and attitudes towards NST, and a summary of educational programmes and initiatives throughout the world. Another lecture discussed the applications of NST in everyday life and provided examples that are familiar to secondary school students. The latter presentation introduced some classroom activities developed in the University of Jyväskylä, demonstrating the size scale of nano-objects, the properties of ferrofluids, and the operating principle of the atomic force microscope. None of the lectures gave strong suggestions on the educational significance of NST nor how to incorporate these topics into the curriculum. These questions were mainly left to the teachers' own discretion.

Thus, despite these few lectures, the course clearly focused on content knowledge rather than pedagogical content knowledge (Shulman, 1986) of NST. However, the interpretation of content knowledge was a comparatively broad one, in the same way as in the Model of Educational Reconstruction's analysis of content structure (Duit, 2007): "content" involves not only scientific concepts and their relations but also knowledge on the nature and processes of science as well as its interrelationships with society.

The breadth of the course content may be evaluated by comparing the programme to the systematic reviews of the whole domain of NST published recently. The programme clearly covers all nine "Big Ideas" of nanoscale science and engineering compiled in a thorough Delphi study by Stevens et al. (2009). Furthermore, when compared to the comprehensive summary of NST-fields by Brune et al. (2006), the course does address at least some of the issues in each branch of research related to "Materials", "Information Storage" as well as "Biomedical Opportunities \& Applications" (Tables 1, 2, and 3.3 in Brune et al., 2006). On the basis of these comparisons, the course seems to have provided the participants with quite an extensive, all-round image of NST.

\section{Questionnaire}

Course participants' views on the need and prospects of NST education in secondary schools were studied using a written questionnaire (see English translation of the questionnaire in Appendix A). The first five questions gathered some background information on the respondents. The rest of the questions were open-ended, broad and open by nature. They aimed at helping the respondents ponder the issues related to the research question from several viewpoints: regarding the current state, need, contents, resources and constraints for NST education at secondary school. The survey forms were handed to all the participants in the opening of the final day of the course, with a request to anonymously fill in and return them during the day. 
To strive for objectivity, the standard that is commonly considered problematic in qualitative content analysis (cf. Patton, 1990), the questionnaire was designed in a way that avoids giving suggestions to the respondents. It can also be presumed that the teachers answered the anonymous questionnaire sincerely. Objectivity of the research method is elaborated further in the concluding section.

\section{Respondents}

By the end of the course, 23 filled-in questionnaire forms were collected. Four course participants did not attend the final day when the survey was conducted, and two participants did not return the questionnaire.

Genders were represented quite evenly among the respondents: 13 women and 10 men. The respondents were highly experienced teachers: on average they had over 20 years of teaching experience. Of the total respondents, 14 were teaching in upper secondary school (ages 16-18), 11 in lower secondary school (ages 13-15) - i.e. two teachers taught at both levels. All the teachers were teaching physics either as their primary or secondary subject, except for one, who was a teacher of chemistry and biology. Most of the respondents were giving courses in mathematics and chemistry as well.

The study employed purposeful sampling that is typical for qualitative inquiry with small samples (e.g. Miles \& Huberman, 1994; Patton, 1990). By selecting information-rich cases, one can gain valuable, in-depth knowledge of the issues of interest. Indeed, the respondents in this study can be considered as experts when it comes to views on NST teaching in schools. Firstly, because of their broad professional experience, the respondents are familiar with the curriculum and school work in practice, including all the possibilities, needs and constraints. It can be assumed that they are able to point out potential barriers (Bamberger \& Krajcik, 2010; Ertmer, 1999) that hinder incorporating NST into the curriculum. Secondly, due to the training the respondents were clearly more aware and informed of the fields in question than Finnish school teachers on average. Thus, the respondents were especially capable of analysing NST from an educational viewpoint, and their opinions are definitely worth taking into account. Using the terms of the Model of Educational Reconstruction, the respondents in this study are competent in estimating the educational significance of NST (cf. Duit, 2007).

Since the participation in the training course was fully voluntary, the respondents are presumably more interested in NST, and/or in-service training in general, than the average teacher. Also, all the teachers were from the Helsinki area, and they were somewhat older than the average secondary school teacher. The study does not culminate in generalisations to a larger group of teachers. Typically, generalisations from studies of this kind are analytic ones, not "sample-to-population" (cf. Miles \& Huberman, 1994, p. 279). The choice of qualitative approach and purposeful sampling was driven by conceptual questions, not by concerns for representativeness.

\section{Content analysis}

The research question was approached by means of qualitative content analysis on the returned questionnaires. The content analysis aimed at identifying and categorising similarities and analogies in responses (cf. Patton, 1990), i.e. finding patterns that characterise respondents' ideas concerning the research question. Every answer form was analysed as a whole. First, three general themes in teachers' responses were identified: the perceived need and reasons for NST education, ideas for important content areas, and opinions on the resources for NST instruction. The analysis was then carried out by scrutinising all the gathered responses from the viewpoint of one of these themes at a time. 
Reliability of the analysis (cf. Miles \& Huberman, 1994) must be discussed with respect to the study's close connection to the training course. The fact that the respondents' ideas were, to an extent, inspired by the course content should not be seen as a threat to the study's reliability, but seen rather as a key feature in the frame of the study. In order to ensure the reliability of the study, content analysis of the responses is carried out with reasonable care, using a simple classification method. The responses, presented in the following section, appeared to be credible in terms of coherency with one another, with the setting of the study, and with the literature (cf. ibid, p. 278279). However, the credibility of the findings concerning the educational significance of NST may be questioned because of the one-sidedness of the research frame. It was beyond the scope of this study to invite the teachers to analyse the educational significance of NST in comparison to some other fields of science and technology.

\section{RESULTS \& DisCUSSION}

\section{The three themes in teachers' responses}

The data gathered in the study was fairly broad. Although some teachers answered only with one sentence per question, even in those cases the responses appeared quite considered. The respondents had clearly spent a good amount of time with the questionnaire during the final day of the course.

Three themes were identified in the qualitative content analysis of the teachers' responses: (i) general views on the educational significance of NST and the need to include them into curriculum; (ii) views on educationally important content areas of NST; and (iii) views on resources for providing instruction on NST in secondary school. All 23 respondents had expressed at least some ideas concerning all three of these themes.

The respondents' sentences, written anywhere in the questionnaire, were then categorised into the three themes. One sentence could also belong to more than one theme - this was the case on several occasions. For example, the following answer was given to question 12 by one teacher:

They [NST] could motivate students to further studies in physics, chemistry and biology, if

there would be good instructional materials readily available. The applications are especially relevant also in this sense.

This answer was considered to inform all of the three themes: the idea of increasing motivation was registered in the first theme (the rationales), applications in the second theme (the contents), and the need for ready-to-use materials in the third theme (the resources).

After the categorisation of the responses, the material in every category (theme) was reviewed as a whole in order to find the common ideas among the respondents. In the following, the results of the analysis are discussed by scrutinising each of the three themes at a time.

\section{(i) Respondents' opinions on the need for NST teaching in secondary school}

According to the content analysis on the responses, the issues of NST had not been discussed in respondents' science lessons except in passing. Usually the issues had been mentioned just incidentally in the context of scales and units; for example, that the prefix "nano" means $10^{-9}$. Only some teachers had presented a definition of NST to their students, and a few had discussed them as a potential field of study. The lack of NST-issues in the respondents' teaching was an expected finding, since Finnish secondary school curriculum does not refer to the fields of NST explicitly (FNBE, 2003, 2004). Discussing them in school depends fully on the teachers' own activity and interest in these fields - and in science lessons there is little room for extra-curricular contents. There is, however, at least some congruence between the contents of science curriculum and the fundamental concepts of NST. The potential of these interfaces is discussed in the following sections. 
Despite the lack of NST in their current teaching, the respondents agreed that NST should be taught in school. They justified this opinion especially by referring to the general importance of the fields in terms of all-round education: everyone should have knowledge of NST in the light of nanotechnological products and applications, their societal significance, and the prospects for the future. Typical answers of this kind were e.g.

Nanotechnological applications are already present in students' lives today, not to mention their large potential just round the corner.

Soon all citizens should know what it [NST] is about.

Additionally, most teachers found that discussing NST in school might be important regarding further studies and working life. Many respondents also suggested that addressing the topics in lessons might increase students' interest in science and technology in general. Only two teachers had major reservations about discussing NST in school; they argued that the curriculum is already full, and NST still bears too much uncertainty and too many tenuous issues. Apart from these critical views, all the other respondents highlighted the same educational needs that are generally used in promoting NST education (see Introduction).

The respondents preferred the incorporation of NST into the curriculum as a transdisciplinary theme, discussed in the context of the traditional school subjects. All the teachers suggested physics and chemistry as suitable subjects for this, but also biology, mathematics and even handicraft and health education were mentioned. None of the respondents thought that NST should be constituted as a new subject in school - at least not for now. According to the teachers, there is currently no room for another subject in the curriculum. Most of the teachers emphasised that there is no need for that either, since NST can be integrated into existing subjects:

It would be enough if nano-issues are discussed in some physics / chemistry / biology courses.

Societal implications aren't a reason to change the conventional division [of the disciplines]. Many respondents, however, proposed a special, optional course in NST in upper secondary school. Generally the teachers stressed that NST should be discussed only a little in lower secondary school, and more in upper secondary school.

\section{(ii) Respondents' opinions on educational significance of different content areas of NST}

All of the surveyed teachers pointed out that the products and applications of NST belong to an educationally significant content area that should be addressed in school. Most of the respondents mentioned applications just generally, but some were more specific: e.g. medicine, electronics and coatings were suggested as important fields of application. Several teachers argued that the focus should be on applications particularly in lower secondary school:

In lower secondary school the products that are important regarding everyday life [should be discussed], in upper secondary school also other issues that are important in the sense of all-round education.

Just applications in lower secondary school, the science is too hard [for that level].

Respondents' consensus on the central educational importance of nanotechnological applications is an interesting finding. The general public associates NST strongly with products of nanotechnology since the mass media typically focuses on them, but science teachers' perspective is generally somewhat different. They presumably look at a research field from the viewpoint of the general goals of science education and curriculum that emphasises an understanding of scientific concepts and principles (see e.g. Pehkonen et al., 2007). Furthermore, the training course went beyond the applications and provided scientific explanations on the phenomena and properties that emerge on the nanoscale. Thus, the respondents' unanimous opinion should be considered as being an informed one. 
Many teachers, however, also stressed the importance of NST-related scientific principles, the conception of size and scale, and the research methods and manufacturing techniques. Typical suggestions for themes in secondary school instruction were e.g.

Self-assembly is an important principle.

What does the 'smallness' mean; the basics about dimension.

The scale and how things can be controlled.

How we can see into matter.

Production of nanoparticles, nanotubes, nanowires.

Additionally, the respondents raised ethical issues related to NST as a worthwhile topic for secondary schools. The risks concerning health and the environment were specified in many responses. According to the teachers, the futuristic visions and prospects should also be addressed in education.

In summary, the respondents pointed out essentially the same educationally significant issues that were nominated as the "Big Ideas" of NST by Stevens et al. (2009). That list was compiled for grades 7-9 (lower secondary school), but it essentially coincides with another list of key ideas for grades 10-12 (upper secondary school) that also was put together through experts' consensus by Wansom et al. (2009). The first four "Big Ideas" ("Size and Scale", "Structure of Matter", "Forces and Interactions" and "Quantum Effects"), related to the foundational science content, were explicitly mentioned by the teachers - except for the latter one. Either the teachers did not find quantum effects essential in the domain of NST, or they considered the topic too difficult or otherwise inappropriate for secondary level - after all, quantum physics plays quite an insignificant role in the Finnish curriculum (FNBE, 2003, 2004). The remaining "Big Ideas" - "Size-Dependent Properties", "Self-Assembly", "Tools and Instrumentation", "Models and Simulations" and "Science, Technology and Society" (Stevens et al., 2009) - do not relate directly to foundational science content but rather to the phenomena, applications, methods and interrelationships that are specific to NST. They do not have many connections to current curriculum contents, contrary to the first four ideas pertaining to basic science. Even then, the respondents highlighted every one of these "applied" ideas as being educationally significant. This congruence took place although the "Big Ideas" were not presented to the participants at any time during the course, nor used when planning the course programme.

The major difference between the educationally significant issues obtained in this study and the "Big Ideas" of NST by Stevens et al. (2009) is that the latter focuses solely on the scientific principles and processes, addressing applications and implications only generally in the last "Big Idea". On the contrary, the Finnish NST-trained science teachers emphasised the importance of practical applications. Another interesting finding is that only a few teachers mentioned that secondary level students may have conceptual difficulties in understanding the nanoscale science. A similar finding was made by Bamberger and Krajcik (2010); also their respondents argued that NST would meet the capacities of this age group.

\section{(iii) Respondents' opinions on resources for NST teaching}

When it comes to organising instruction on NST in practice, the respondents expressed very sceptical views. The teachers were unanimous in their estimation: currently their schools have only poor resources or no resources at all to provide education on the topics in question. The respondents pointed out several problems related to physical and mental resources. Still, all of the teachers emphasised that in-service teacher training would be the key issue to improve the capabilities:

Teacher training would be the number one thing, and inspiring the teachers.

Teachers are willing to educate themselves.

Besides the need for supplementary training, all the responses to the questionnaire brought out the fundamental needs for money and time in order to organise instruction in NST in practice: 
Currently it is hard to arrange any special courses in upper secondary school - the resources are hardly enough even for the basic courses.

The courses are full-packed already.

If there is money, a special course can be created on any topic.

In these typical quotations one can see the two basic lines of teachers' arguments. Incorporating NST into existing science courses appears difficult since these topics are not explicitly in the Finnish curricula (FNBE, 2003, 2004), and there is hardly any space for additional contents. On the other hand, arranging extra courses (optional for upper secondary school students) requires money for teacher person-hours. Many respondents expressed that addressing NST in science lessons depends completely on themselves and other individual teachers:

Based on the knowledge I gain in this course, I will build a Power point presentation on nanotechnology.

It depends, and will depend for a long time on individuals' activeness.

Accordingly, several respondents stressed that bringing NST into secondary school requires a change of national curriculum standards. The dilemma in the modernization of school science shows in the following citation:

New physics is developed all the time. It should be taught in upper secondary school, and is based on pre-existing [physics]. The beginning has to be learned before it's possible to learn about the last part. There is so much knowledge, that you cannot learn it in 3 years. We are already on the extreme limits. What should be taught less, if something is added in?

In comparable studies by Bamberger and Krajcik (2010) and Hutchinson, Bryan and Daly (2009), American science teachers expressed similar views: time constraints essentially hinder NST teaching as the topics are not in the national standards explicitly, even if there are implicit connections. Similar findings have been made in other curriculum innovations (cf. Anderson \& Helms, 2001; Peers et al., 2003).

Furthermore, according to the NST-informed teachers surveyed in this study, bringing NST into classrooms presumes instructional materials (textbooks, web materials, DVDs etc.) as well as instruments for experimental work:

One good textbook would help to get started.

Ready-to-use materials would be nice. And an atomic force microscope would be nice...

Also in the study by Bamberger and Krajcik (2010), teachers expressed the need for researchbased teaching materials. Although some instructional materials have recently been developed (e.g. Stevens et al., 2009), there are hardly any textbooks available that are suitable for secondary level, and none in Finnish. An increasing amount of educational materials are available on the Internet, but again there are none in Finnish yet. Another challenge is the instruments required for arranging experimental work or hands-on activities. Recently, such methods have been developed especially in the U.S. (see Sweeney \& Seal, 2008).

Additionally, the surveyed teachers called for co-operation with universities and enterprises. Successful practices for university-school partnerships in teaching contemporary sciences such as NST have been reported worldwide (ibid), but in Finland no partnerships on NST have yet been initiated. Whereas when it comes to school group visits to industry and enterprises as a part of science and technology education, Finland has a long tradition (Lavonen et al., 2009). There are many nanotechnology-related companies in Finland, so the respondents' suggestion for discussing NST by means of industry visits seems like a feasible method. 


\section{CONCLUSIONS}

The purpose of the study was to analyse the perceived need for education in NST, conceivable content matters that should be addressed in education, and the related curricular issues. The study, thereby, followed the philosophic tradition of curricular inquiry (Darling-Hammond \& Snyder, 1992). The idea was to analyse the educational significance (Duit, 2007) of NST by empirical means - using an expert survey. There are several groups of experts that are to be consulted in the process of science curriculum revision; for example, education policy makers and scientists. This study, however, focused on the views of science teachers with some expertise in NST. Given the crucial role of teachers in curricular processes (Kelly, 2004; van Driel et al., 2001), those views are worth taking into account. The results give rise to implications in the development of curriculum and instructional materials both in Finland and, taking the local setting into consideration, also abroad.

The main challenge to objectivity of this study seems to arise from the course programme that clearly had an effect on teachers' views of NST. This influence can be seen in teachers' responses, e.g. concerning the issues they pointed out as being the most important concepts and fields of NST. It is hardly a coincidence that all the topics the respondents proposed as educationally important ones were somehow included in the course programme (not vice versa, however). Still, teachers' views should be considered as their own conclusions, since the course consisted of a number of separate presentations and did not provide such conclusions on the main issues. The week-long course was quite varied and comprehensive; it may be assumed that the course content did not emphasize any specific aspect too much. Moreover, the course was strongly focused on providing the participants with an all-round content knowledge (Shulman, 1986) of NST, instead of pedagogical aspects. It seems likely that the experienced teachers were able to use the course as a source of diversified information on NST-related issues and to reflect that information critically on the basis of their experience and views on science education.

The surveyed teachers considered that NST should be taught in school. Chiefly the respondents highlighted the meaning of NST for everyday life and citizenship; this was no surprise since the Finnish secondary school has a strong orientation towards all-round education (see e.g. Pehkonen et al., 2007). Additionally, several teachers pointed out the importance of NST for further studies and science-related careers, and also these fields' potential to enhance the general interest in science and technology was often mentioned. The respondents' arguments thereby cover the same rationales that have been generally used in the recent demands for NST education (cf. Laherto, 2010). These rationales can also be discussed in terms of the general purposes of science and technology education by using, for instance, the two visions of scientific literacy suggested by Roberts (2007). In his terms, the teachers in this study emphasised the educational aims connected to the Vision II of scientific literacy (starting with situations, proceeding to science that is relevant in them) rather than the Vision I (looking inward to science itself).

In line with this view, the respondents considered the nanotechnological products and applications as the most important aspect of NST to be taught in secondary schools. Such knowledge may indeed be most important for the purposes of everyday life and active citizenship. Nevertheless, any kind of scientific literacy requires at least some knowledge of science and knowledge about science as well (ibid). According to the highly influential conceptualisation by Miller (1983), scientific literacy consists of (a) an understanding of the norms and methods of science (i.e., the nature of science); (b) an understanding of key scientific terms and concepts (i.e., science content knowledge); and (c) an awareness and understanding of the impact of science and technology on society. Accordingly, while the teachers in this study accentuated the latter (also covering NST-related ethical issues), they also rated the methods and processes of NST (a) and the central scientific concepts and ideas (b) as educationally significant. 
The respondents did not, however, consider quantum mechanics as a necessity when discussing NST in secondary school. This is interesting, since the phenomena and properties which make NST scientifically and technologically novel are essentially caused by the quantum effects (except for the phenomena based on of the classically understood scaling effects; see Brune et al., 2006). Still, teachers' position is understandable given their view of the purpose of NST education. It can be argued that the social and environmental implications of NST, for example, can be grasped without the scientific explanations for the discontinuous change of properties at a certain size. Secondary level NST education could, thereby, stay at the macroscopic manifestations of nanoscale phenomena, and their implications.

Many respondents pointed out the educationally significant issues' close relations to the science content that is already in the curriculum. Thus, the respondents mostly preferred the incorporation of NST as a transdisciplinary theme in the context of current school subjects. Such an integrative approach seems to fit especially well into the teaching of the fundamental scientific concepts that NST is based on, i.e. the first four "Big Ideas", since they are already discussed to some degree in the secondary level curriculum (FNBE, 2003, 2004). Incorporating the applications of NST, as emphasized by the respondents, into the curriculum may be more challenging due to the curricular limitations pointed out in the study. On the basis of the results of the survey it thus seems that the essential issues of NST do not fit into the curriculum just by adding them, but rather would require a more thorough curriculum revision. Accordingly, in the recent literature on science education policies, NST has even been proposed as the route to a new kind of interdisciplinary curriculum or "catalyst for educational reform" (Schank, Krajcik \& Yunker, 2007). Stevens et al. (2009) advocate coherence in the science curriculum and suggest the "Big Ideas" of NST as its foundation - although admitting that in practice achieving this kind of fundamentally interdisciplinary NST teaching is "more complex than simply adding NSE examples into current lessons or inserting an NSE module into the current curriculum" (ibid, p. ix).

However, the respondents argued that to teach any of this would require in-service training in NST, above all. The results strongly suggest that such programmes for secondary level teachers should be arranged, if NST is to be included in the curriculum. The respondents in the study, thereby, perceived the same need that has been surfacing worldwide; e.g. the "Big Ideas" project highlights teacher preparation as a significant challenge "to the goal of an NSE-educated citizenry" (ibid, p. 173-178). Furthermore, the respondents' views reported here should be taken into account when developing courses, materials and methods. The teachers' ideas on resources for NST teaching correspond with the views of American teachers in the recent studies by Hutchinson, Bryan and Daly (2009), and Bamberger and Krajcik (2010). The primary barriers perceived by the teachers were extrinsic ones in these studies also.

All in all, the results of the present study are quite parallel to the previous results of the aforementioned American studies on the educationally important aspects and teachers' barriers related to NST. Yet, the meaning of the study is still more than confirmatory. Firstly, development of curriculum always requires locally laid groundwork; the teachers who are implementing the curriculum innovation must be heard in the first place (cf. Anderson \& Helms 2001; Peers et al. 2003; van Driel et al., 2001). The previous studies of this kind were all carried out within the U.S. educational system, somewhat different from the Finnish one (see Pehkonen et al., 2007). Secondly, contrary to the earlier studies, the surveyed teachers were quite thoroughly trained in NST content knowledge - but not in pedagogical content knowledge - before answering the questionnaire. This increased certain value for the information acquired from the respondents, as discussed in the paper. 


\section{REFERENCES}

Anderson, R., \& Helms, J. (2001). The ideal of standards and the reality of schools: Needed research. Journal of Research in Science Teaching, 38(1), 3-16.

Bamberger, Y., \& Krajcik, J. (2010). The role of teachers' barriers in integrating new ideas into the curriculum: The case of nanoscale science and technology. Paper presented at the Annual Conference of the National Association of Research in Science Teaching, Philadelphia, PA.

Brune, H., Ernst, H., Grunwald, A., Grünwald, W., Hofmann, H., Krug, H., Janich, P., Mayor, M., Rathgeber, W., Schmid, G., Simon, U., Vogel, V., \& Wyrwa, D. (2006). Nanotechnology: Assessment and perspectives. Berlin Heidelberg: Springer.

Darling-Hammond, L., \& Snyder, J. (1992). Curriculum studies and the traditions of inquiry: The scientific tradition. In P. W. Jackson (Ed.), Handbook of research on curriculum (pp. 41-78). New York: Macmillan.

Duit, R. (2007). Science education research internationally: Conceptions, research methods, domains of research. Eurasia Journal of Mathematics, Science \& Technology Education, 3(1), 3-15.

Duit, R., Komorek, M., \& Wilbers, J. (1997). Studies on educational reconstruction of chaos theory. Research in Science Education, 27(3), 339-357.

Ertmer, P. (1999). Addressing first- and second-order barriers to change: Strategies for technology integration. Educational Technology Research and Development, 47(4), 47-61.

European Commission (2010). Report on the European Commission's public online consultation: Towards a strategic nanotechnology action plan (SNAP) 2010-2015. Belgium: European Communities.

FNBE (2003). National core curriculum for upper secondary schools. Helsinki: Finnish National Board of Education.

FNBE (2004). National core curriculum for basic education. Helsinki: Finnish National Board of Education.

Hutchinson, K., Bryan, L., \& Daly, S. (2009). Mediators of middle- and high-school teachers' integration of nanoscale science and engineering content into their curriculum. Paper presented at the Annual Conference of the National Association of Research in Science Teaching, San Diego, CA.

Kelly, A. (2004). The curriculum - theory and practice (5th ed.). London: SAGE.

Komorek, M., Wendorff, L., \& Duit, R. (2002). Expertenbefragung zum Bildungswert der Nichtlinearen Physik [Views of experts on the educational potential of nonlinear physics]. Zeitschrift für Didaktik der Naturwissenschaften, 8, 33-51.

Laherto, A. (2010). An analysis of the educational significance of nanoscience and nanotechnology in scientific and technological literacy. Science Education International, 21(3), 160-175.

Lavonen, J., Laherto, A., Loukomies, A., Juuti, K., Kim, M., Lampiselkä, J., \& Meisalo, V. (2009). Enhancing scientific literacy through the industry site visit. In S. Rodrigues (Ed.), Multiple literacy and science education: ICTs in formal and informal learning environments (pp. 225239). Hershey, PA: Information Science Reference.

Miles, M., \& Huberman, A. (1994). Qualitative data analysis (2nd ed.). Thousand Oaks, CA: SAGE.

Miller, J. (1983). Scientific literacy: A conceptual and empirical overview. Daedalus, 112(2), 29-48.

Ministry of Education (Finland) (2005). Nanoscience spearheads in Finland. Report no. 2005:39. Helsinki: Ministry of Education.

Mitchell, M. (2007). Scientific promise: Reflections on nano-hype. In N. de S. Cameron \& M. Mitchell (Eds.), Nanoscale: Issues and perspectives for the nano century (pp. 43-60). Hoboken, NJ: John Wiley \& Sons.

Moor, J., \& Weckert, J. (2004). Nanoethics: Assessing the nanoscale from an ethical point of view. In D. Baird, A. Nordmann, \& J. Schummer (Eds.), Discovering the nanoscale (pp. 301-310). Amsterdam: IOS Press. 
Patton, M. (1990). Qualitative evaluation and research methods. Newbury Park, CA: Sage Publications.

Peers, C., Diezmann, C., \& Watters, J. (2003). Supports and concerns for teacher professional growth during the implementation of a science curriculum innovation. Research in Science Education, 33(1), 89-110.

Pehkonen, E., Ahtee, M., \& Lavonen, J. (Eds.) (2007). How Finns learn mathematics and science. Rotterdam: Sense Publishers.

Roberts, D. (2007). Scientific literacy/Science literacy. In S.K. Abell \& N.G. Lederman (Eds.), Handbook of research on science education (pp. 729-780). Mahwah, NJ: Lawrence Erlbaum Associates.

Schank, P., Krajcik, J., \& Yunker, M. (2007). Can nanoscience be a catalyst for education reform? In F. Allhoff, P. Lin, J. Moor \& J. Weckert (Eds.), Nanoethics: The ethical and social implications of nanotechnology (pp. 277-290). Hoboken, NJ: Wiley Publishing.

Shulman, L. (1986). Those who understand: Knowledge growth in teaching. Educational Researcher, 15(2), 4-14.

Stevens, S., Sutherland, L., \& Krajcik, J. (2009). The big ideas of nanoscale science and engineering. Arlington, VA: NSTA Press.

Sweeney, A., \& Seal, S. (Eds.) (2008). Nanoscale science and engineering education. Stevenson Ranch, CA: American Scientific Publishers.

van Driel, J., Beijaard, D., \& Verloop, N. (2001). Professional development and reform in science education: The role of teachers' practical knowledge. Journal of Research in Science Teaching, 38(2), 137-158.

Wansom, S., Mason, T., Hersam, M., Drane, D., Light, G., Cormia, R., Stevens, S., \& Bodner, G. (2009). A rubric for post-secondary degree programs in nanoscience and nanotechnology. International Journal of Engineering Education, 25(3), 615-627.

Zenner, G., \& Crone, W. (2008). Introducing nanotechnology and society issues into the classroom. In A. Sweeney \& S. Seal (Eds.), Nanoscale science and engineering education (pp. 622-647). Stevenson Ranch, CA: American Scientific Publishers. 


\section{Appendix A}

Questionnaire for the participants of the course "Nanoscience and nanotechnology" English translations by the author (questionnaire originally in Finnish)

\section{$\underline{\text { Background information }}$}

1. Gender (female/male)

2. Age (20-29/30-39/40-49/50-59/60+ years)

3. Teaching experience years)

4. At which level(s) did you teach during the last school year? (primary/lower secondary/upper secondary school)

5. In which subjects are you teaching? Please mention first the one in which you are teaching the most.

\section{Conceptions about nanoscience and nanotechnology in school}

6. To what extent have you discussed nanoscience and nanotechnology in your classes?

7. Should nanoscience and nanotechnology be taught in lower/upper secondary school? Why or why not?

8. In which classes should nanoscience and nanotechnology be discussed?

9. Should nanoscience and nanotechnology be constituted as a new subject in lower/upper secondary school? Why or why not?

10. Which issues of nanoscience and nanotechnology should be discussed in lower/upper secondary school?

11. In your estimation, how are the resources (material resources, time resources, teachers' resources) for providing tuition in nanoscience and nanotechnology related issues? What should be done in order to improve those resources?

12. What else would you like to say about nanoscience and nanotechnology instruction in school?

13. If you want, please give feedback about this week's training course! 